\title{
Controlled crystal growth of layered-perovskite thin films as an approach to study their basic properties
}

\author{
Takayuki Watanabe ${ }^{\text {a) }}$ and Hiroshi Funakubo ${ }^{\text {b) }}$ \\ Department of Innovative and Engineered Materials, Interdisciplinary Graduate School of Science \\ and Engineering, Tokyo Institute of Technology, Yokohama 226-8502, Japan
}

(Received 14 March 2005; accepted 27 December 2005; published online 8 September 2006)

This article describes the current progress in thin bismuth layer-structured ferroelectric films (BLSFs) including $\mathrm{SrBi}_{2} \mathrm{Ta}_{2} \mathrm{O}_{9}$ and $(\mathrm{Bi}, \mathrm{La})_{4} \mathrm{Ti}_{3} \mathrm{O}_{12}$, particularly those developed in the last ten years. BLSF thin films can be applied to ferroelectric random access memories because of their durable fatigue-free properties and lead-free composition. We will briefly introduce epitaxial thin films grown on a variety of substrates. Because of the difficulty in growing single crystals of sufficient size to characterize the ferroelectric behavior in specific crystal growth directions, we will characterize epitaxially grown thin films to obtain basic information about the anisotropic switching behavior, which is important for evaluating the performance of emerging materials. We will then discuss the fiber-textured growth on the (111)Pt-covered $\mathrm{Si}$ substrates of $\mathrm{SrBi}_{2} \mathrm{Ta}_{2} \mathrm{O}_{9}$ and $\mathrm{Bi}_{4} \mathrm{Ti}_{3} \mathrm{O}_{12}$ thin films. Because we expect that the spread crystal orientation will affect the bit-to-bit errors, we believe that the fiber-textured growth and the characterization technique for the deposited film orientation are interesting from a practical standpoint. Another specific challenge of thin film growth is the growth of $a$-axis-(polar axis)-oriented films. $a$ - $/ b$-axis-oriented films are characterized both crystallographically and by electric hysteresis loop. The hysteresis performance was in accordance with the volume fraction of the $a / b$ domains; however, no evidence for $90^{\circ}$ switching of the $b$ domain by an external electric field was obtained. The control of film orientation also allows systematic studies on the effects of a structural modification and relation between spontaneous polarization and Curie temperature, examples of which are given in this paper. After a short description of the piezoelectric properties, we will conclude with a summary and the future prospects of BLSF thin films for research and applications. (c) 2006 American Institute of Physics. [DOI: $10.1063 / 1.2337357$ ]

\section{INTRODUCTION}

In 1950, Aurivillius reported on a series of layerstructured crystals currently called bismuth layer-structured ferroelectrics (BLSFs) or the Aurivillius family. ${ }^{1,2}$ Their most distinctive structural feature is the intergrowth of the perovskitelike slab (pseudoperovskite layer) and bismuth oxide layers along the $c$-axis. The chemical formula is widely described as $\left(\mathrm{Bi}_{2} \mathrm{O}_{2}\right)^{2+}\left(A_{m-1} B_{m} \mathrm{O}_{3 m+1}\right)^{2-}$, where $A$ represents the mono-, di-, or trivalent ions $\left(\mathrm{Na}^{+}, \mathrm{Sr}^{2+}, \mathrm{Ba}^{2+}, \mathrm{Pb}^{2+}, \mathrm{Ca}^{2+}\right.$, $\mathrm{Bi}^{3+}$, lanthanoid ions, etc.), $B$ represents the tetra-, penta-, or hexavalent ions $\left(\mathrm{Ti}^{4+}, \mathrm{V}^{5+}, \mathrm{Ta}^{5+}, \mathrm{Nb}^{5+}, \mathrm{Mo}^{6+}, \mathrm{W}^{6+}\right.$, etc. $)$, and $m$ represents the number of $\mathrm{BO}_{6}$ octahedra in the pseudoperovskite layer. Figure 1 shows the crystal structures of the representative $\mathrm{SrBi}_{2} \mathrm{Ta}_{2} \mathrm{O}_{9}(\mathrm{SBT}, m=2)$ and $\mathrm{Bi}_{4} \mathrm{Ti}_{3} \mathrm{O}_{12}$ (BIT, $m=3$ ) BLSFs. Almost all BLSFs have orthorhombic symmetry at room temperature (that of $\mathrm{Bi}_{4} \mathrm{Ti}_{3} \mathrm{O}_{12}$ is strictly monoclinic). A variety of over 50 materials with different $m$ numbers typically ranging from 1 to 5 , or a combination of them, have been reported and are considered to be ferroelectrics. The spontaneous polarization $\left(P_{s}\right)$ originates from the rota-

\footnotetext{
${ }^{a}$ Also at Institute of Solid State Research and CNI (Center of Nanoelectronic Systems for Information Technology) Research Center Juelich, D-52425 Juelich, Germany; electronic mail: t.watanabe@fz-juelich.de

${ }^{b)}$ Also at Precursory Research for Embryonic Science and Technology (PRESTO), Japan Science and Technology Corporation (JST), Kawaguchi 332-0012, Japan; electronic mail: funakubo@iem.titech.ac.jp
}

tion and tilt of the octahedrons. ${ }^{3-8}$ Interestingly, even$m$-numbered BLSFs only exhibit $P_{s}$ along the $a$-axis because of the glide and mirror planes perpendicular to the $b$ - and $c$-axes, while odd- $m$-numbered BLSFs exhibit minor $P_{s}$ along the $c$-axis and major $P_{s}$ along the $a$-axis when the glide planes are perpendicular to the $b$-axis. Some typical BLSFs are listed in Table I., ${ }^{1,9-29}$

In the early stages, BLSFs were investigated for use in potential optoelectronic and piezoelectronic devices. ${ }^{30-34}$ However, the number of these research materials dramatically increased after the fatigue-free nature of SBT ferroelectric capacitors coupled with Pt electrodes was discovered in $1995{ }^{35}$ The high-fatigue endurance of these capacitors increased the write/readout cycles of ferroelectric random access memories (FeRAMs) over $10^{10}$. The lead-free composition is also advantageous for addressing environmental issues, because $\mathrm{Pb}(\mathrm{Zr}, \mathrm{Ti}) \mathrm{O}_{3}(\mathrm{PZT})$ is a promising potential material for FeRAMs. In 1999, La-substituted BIT (BLT) showed its fatigue-free nature together with two remarkable advantages: a larger remanent polarization $\left(P_{r}\right)$ and a lower crystallization temperature than those of SBT films. ${ }^{36} \mathrm{Al}-$ though the $P_{s}$ of BIT, $50 \mu \mathrm{C} / \mathrm{cm}^{2}{ }^{13}$ is the largest in BLSFs, the bulk ceramics or BIT thin films are severely influenced by deteriorating polarization ${ }^{15,16,18}$ and fatigue failure, ${ }^{37,38}$ due to the pinning caused by defect complexes ${ }^{15,16,39}$ and the domain structure. ${ }^{40}$ Lanthanoid and/or higher-valent cation 


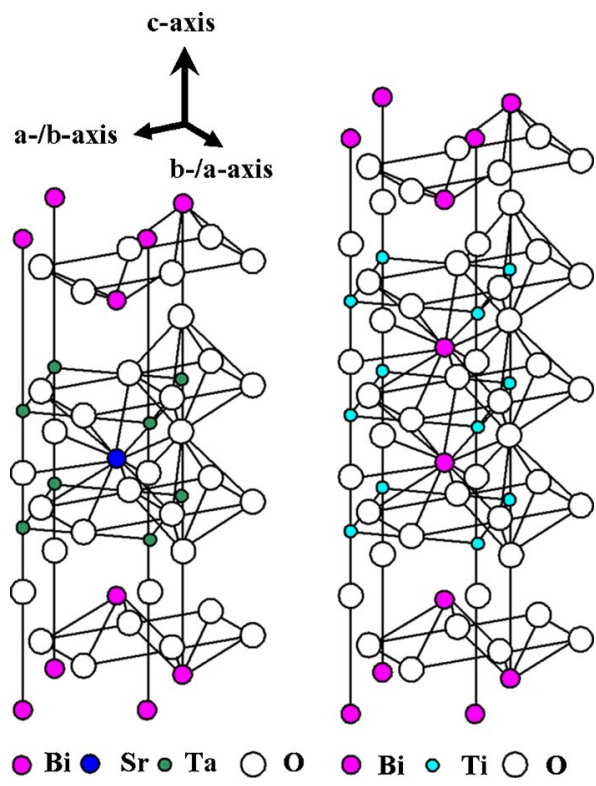

FIG. 1. (Color online) Schematic illustration of $\mathrm{SrBi}_{2} \mathrm{Ta}_{2} \mathrm{O}_{9}$ (left, $Z=4, m$ $=2$ ) and $\mathrm{Bi}_{4} \mathrm{Ti}_{3} \mathrm{O}_{12}$ (right, $Z=4, m=3$ ) crystal structures, which show a halfunit cell along the $c$ axis. The lattice parameters of $\mathrm{SrBi}_{2} \mathrm{Ta}_{2} \mathrm{O}_{9}$ and $\mathrm{Bi}_{4} \mathrm{Ti}_{3} \mathrm{O}_{12}$ are $a=5.52237 \AA, b=5.52408 \AA$, and $c=25.02641 \AA$ and $a$ $=5.44521 \AA, b=5.41118 \AA$, and $c=32.8432 \AA$, respectively (see Refs. 7 and 8). Depending on the $m$ number, the $c$-axis lattice parameter changes at intervals of about $8 \AA$, which corresponds to two perovskite units. The $a / b$ axis is parallel to the diagonal of the pseudoperovskites, so that the $a / b$ axis lattice parameters are approximately root two times the typical lattice parameters of perovskite materials, $4 \AA$.

substitution for $\mathrm{Bi}$ and $\mathrm{Ti}$ sites in the pseudoperovskite layer improve these defects. Recently, it was suggested that Nd-or Pr-substituted BIT [BNT (Refs. 41-43) and BPT (Ref. 44)] films exhibit a comparable large $P_{r}$ of more than $30 \mu \mathrm{C} / \mathrm{cm}^{2}$ for PZT films.

On such background, the primary application considered for BLSF thin films is the FeRAM. Again, the key advantages of these materials compared to PZT are their environmental compatibility and fatigue-free properties, while larger polarization is required for BLSFs to increase the device density. In this review, we will discuss a variety of thin film growths in Secs. II-IV, because the orientation of the individual anisotropic crystals has a large impact on device performance, irrespective of the application. In contrast to cubeon-cube growth or growth in materials with a cubic/ tetragonal perovskite structure, such as the tetragonal $\mathrm{PZT} \| \mathrm{SrTiO}_{3}$, the BLSF crystal structure is always very different from those of the bottom materials. Therefore, thin film growth must be carefully investigated. Subsequently, we will summarize the $P_{s}$ of BLSFs, including emerging materials as a function of the Curie temperature $\left(T_{C}\right)$, in Sec. V to survey the relative positions of the BLSFs in displacive ferroelectrics, followed by a brief report on the piezoelectric properties. Finally, we will conclude with a summary and describe some of the future applications for BLSFs.

\section{EPITAXIAL FILM GROWTH AND FERROELECTRIC PROPERTIES}

BLSF epitaxial films have been grown on single crystal and epitaxially precoated substrates using conductive materials to characterize the structural and electric properties. ${ }^{45-73}$ Because of their structural simplicity, these films are suitable for characterizing the anisotropic properties along a specific crystal direction, such as the dielectric constant, piezoelectric displacement, leakage current, fatigue endurance, and the ferroelectric polarization.

Figure 2 shows typical x-ray diffraction patterns of epitaxially grown BLSF films grown on (100) $\mathrm{SrTiO}_{3}$, (110) $\mathrm{SrTiO}_{3}$, (111) $\mathrm{SrTiO}_{3}$, and (101) $\mathrm{TiO}_{2}$ single crystal substrates using metalorganic chemical vapor deposition (MOCVD), using SBT $(m=2)$ and BIT $(m=3)$ as examples. The crystal orientations of BLSF films grown on the above substrates can be described using the $m$ number as follows: $(001),(11 \underline{m+2}),(10 \underline{m+1}) /(01 \underline{m+1})$, and $(100) /(010)$ orientations, respectively. We confirmed the epitaxial growth using x-ray pole figure measurements, as shown in Fig. 3. As

TABLE I. Aurivillius family layer perovskites (Ln: lanthanoid).

\begin{tabular}{|c|c|c|c|c|c|}
\hline$m$ & 1 & 2 & 3 & 4 & 5 \\
\hline \multirow{10}{*}{ Materials } & $\mathrm{Bi}_{2} \mathrm{VO}_{5.5}$ & $\mathrm{SrBi}_{2} \mathrm{Ta}_{2} \mathrm{O}_{9}$ & $\mathrm{Bi}_{4} \mathrm{Ti}_{3} \mathrm{O}_{12}$ & $\mathrm{SrBi}_{4} \mathrm{Ti}_{4} \mathrm{O}_{15}$ & $\mathrm{Sr}_{2} \mathrm{Bi}_{4} \mathrm{Ti}_{5} \mathrm{O}_{18}$ \\
\hline & $\mathrm{Bi}_{2} \mathrm{MoO}_{6}$ & $\mathrm{CaBi}_{2} \mathrm{Ta}_{2} \mathrm{O}_{9}$ & $\left(\mathrm{Bi}_{4-x} \mathrm{Ln}_{x}\right) \mathrm{Ti}_{3} \mathrm{O}_{12}$ & $\mathrm{BaBi}_{4} \mathrm{Ti}_{4} \mathrm{O}_{15}$ & $\mathrm{Ba}_{2} \mathrm{Bi}_{4} \mathrm{Ti}_{5} \mathrm{O}_{18}$ \\
\hline & $\mathrm{Bi}_{2} \mathrm{WO}_{6}$ & $\mathrm{BaBi}_{2} \mathrm{Ta}_{2} \mathrm{O}_{9}$ & $\mathrm{Bi}_{4-x / 3} \mathrm{Ti}_{3-x} \mathrm{~V}_{x} \mathrm{O}_{12}$ & $\mathrm{PbBi}_{4} \mathrm{Ti}_{4} \mathrm{O}_{15}$ & $\mathrm{~Pb}_{2} \mathrm{Bi}_{4} \mathrm{Ti}_{5} \mathrm{O}_{18}$ \\
\hline & & $\mathrm{PbBi}_{2} \mathrm{Ta}_{2} \mathrm{O}_{9}$ & $\mathrm{Bi}_{4-2 x / 3} \mathrm{Ti}_{3-x} \mathrm{~W}_{x} \mathrm{O}_{12}$ & $\mathrm{CaBi}_{4} \mathrm{Ti}_{4} \mathrm{O}_{15}$ & $\mathrm{Bi}_{6} \mathrm{Ti}_{3} \mathrm{Fe}_{2} \mathrm{O}_{18}$ \\
\hline & & $\mathrm{SrBi}_{2} \mathrm{Nb}_{2} \mathrm{O}_{9}$ & $(\mathrm{Bi}, \mathrm{Ln})_{4}(\mathrm{Ti}, \mathrm{V})_{3} \mathrm{O}_{12}$ & $\mathrm{Bi}_{5} \mathrm{Ti}_{3} \mathrm{FeO}_{15}$ & \\
\hline & & $\mathrm{CaBi}_{2} \mathrm{Nb}_{2} \mathrm{O}_{9}$ & $\mathrm{Bi}_{2} \mathrm{Sr}_{2} \mathrm{Nb}_{2} \mathrm{MnO}_{12-x}$ & $\mathrm{Na}_{0.5} \mathrm{Bi}_{3.5} \mathrm{Ti}_{4} \mathrm{O}_{15}$ & \\
\hline & & $\mathrm{BaBi}_{2} \mathrm{Nb}_{2} \mathrm{O}_{9}$ & $\left(\mathrm{Bi}_{4-x} \mathrm{Sr}_{x}\right)\left(\mathrm{Ti}_{3-x} \mathrm{Nb}_{x}\right) \mathrm{O}_{12}$ & $\mathrm{~K}_{0.5} \mathrm{Bi}_{3.5} \mathrm{Ti}_{4} \mathrm{O}_{15}$ & \\
\hline & & $\mathrm{PbBi}_{2} \mathrm{Nb}_{2} \mathrm{O}_{9}$ & $\left(\mathrm{Bi}_{4-x} \mathrm{Ba}_{x}\right)\left(\mathrm{Ti}_{3-x} \mathrm{Nb}_{x}\right) \mathrm{O}_{12}$ & & \\
\hline & & $\mathrm{Bi}_{3} \mathrm{TiNbO}_{9}$ & $\left(\mathrm{Bi}_{4-x} \mathrm{~Pb}_{x}\right)\left(\mathrm{Ti}_{3-x} \mathrm{Nb}_{x}\right) \mathrm{O}_{12}$ & & \\
\hline & & $\mathrm{Bi}_{3} \mathrm{TiTaO}_{9}$ & & & \\
\hline$m$ & & 1,2 & 2,3 & 3,4 & $\infty$ \\
\hline \multirow[t]{5}{*}{ Materials } & & $\mathrm{Bi}_{2} \mathrm{WO}_{6}-\mathrm{Bi}_{3} \mathrm{Ti}_{1.5} \mathrm{~W}_{0.5} \mathrm{O}_{9}$ & $\mathrm{Bi}_{3} \mathrm{Ti}_{1.5} \mathrm{~W}_{0.5} \mathrm{O}_{9}-\mathrm{Bi}_{4} \mathrm{Ti}_{3} \mathrm{O}_{12}$ & $\mathrm{Bi}_{4} \mathrm{Ti}_{3} \mathrm{O}_{12}-\mathrm{SrBi}_{4} \mathrm{Ti}_{4} \mathrm{O}_{15}$ & $\mathrm{SrTiO}_{3}$ \\
\hline & & $\mathrm{Bi}_{2} \mathrm{WO}_{6}-\mathrm{Bi}_{3} \mathrm{TiNbO}_{9}$ & $\mathrm{Bi}_{3} \mathrm{TiNbO}_{9}-\mathrm{Bi}_{4} \mathrm{Ti}_{3} \mathrm{O}_{12}$ & $\mathrm{Bi}_{4} \mathrm{Ti}_{3} \mathrm{O}_{12}-\mathrm{BaBi}_{4} \mathrm{Ti}_{4} \mathrm{O}_{15}$ & $\mathrm{BaTiO}_{3}$ \\
\hline & & $\mathrm{Bi}_{2} \mathrm{WO}_{6}-\mathrm{Bi}_{2}\left(\mathrm{Bi}_{0.5} \mathrm{Na}_{0.5}\right) \mathrm{NbO}_{9}$ & $\mathrm{Bi}_{3} \mathrm{TiTaO}_{9}-\mathrm{Bi}_{4} \mathrm{Ti}_{3} \mathrm{O}_{12}$ & $\mathrm{Bi}_{4} \mathrm{Ti}_{3} \mathrm{O}_{12}-\mathrm{PbBi}_{4} \mathrm{Ti}_{4} \mathrm{O}_{15}$ & $\mathrm{PbTiO}_{3}$ \\
\hline & & $\mathrm{Bi}_{2} \mathrm{WO}_{6}-\mathrm{Bi}_{3} \mathrm{TaTiO}_{9}$ & $\mathrm{SrBi}_{2} \mathrm{Nb}_{2} \mathrm{O}_{9}-\mathrm{Bi}_{4} \mathrm{Ti}_{3} \mathrm{O}_{12}$ & $\mathrm{Bi}_{4} \mathrm{Ti}_{3} \mathrm{O}_{12}-\left(\mathrm{Na}_{0.5} \mathrm{Bi}_{0.5}\right) \mathrm{Bi}_{4} \mathrm{Ti}_{4} \mathrm{O}_{15}$ & \\
\hline & & & $\mathrm{BaBi}_{2} \mathrm{Nb}_{2} \mathrm{O}_{9}-\mathrm{Bi}_{4} \mathrm{Ti}_{3} \mathrm{O}_{12}$ & & \\
\hline
\end{tabular}



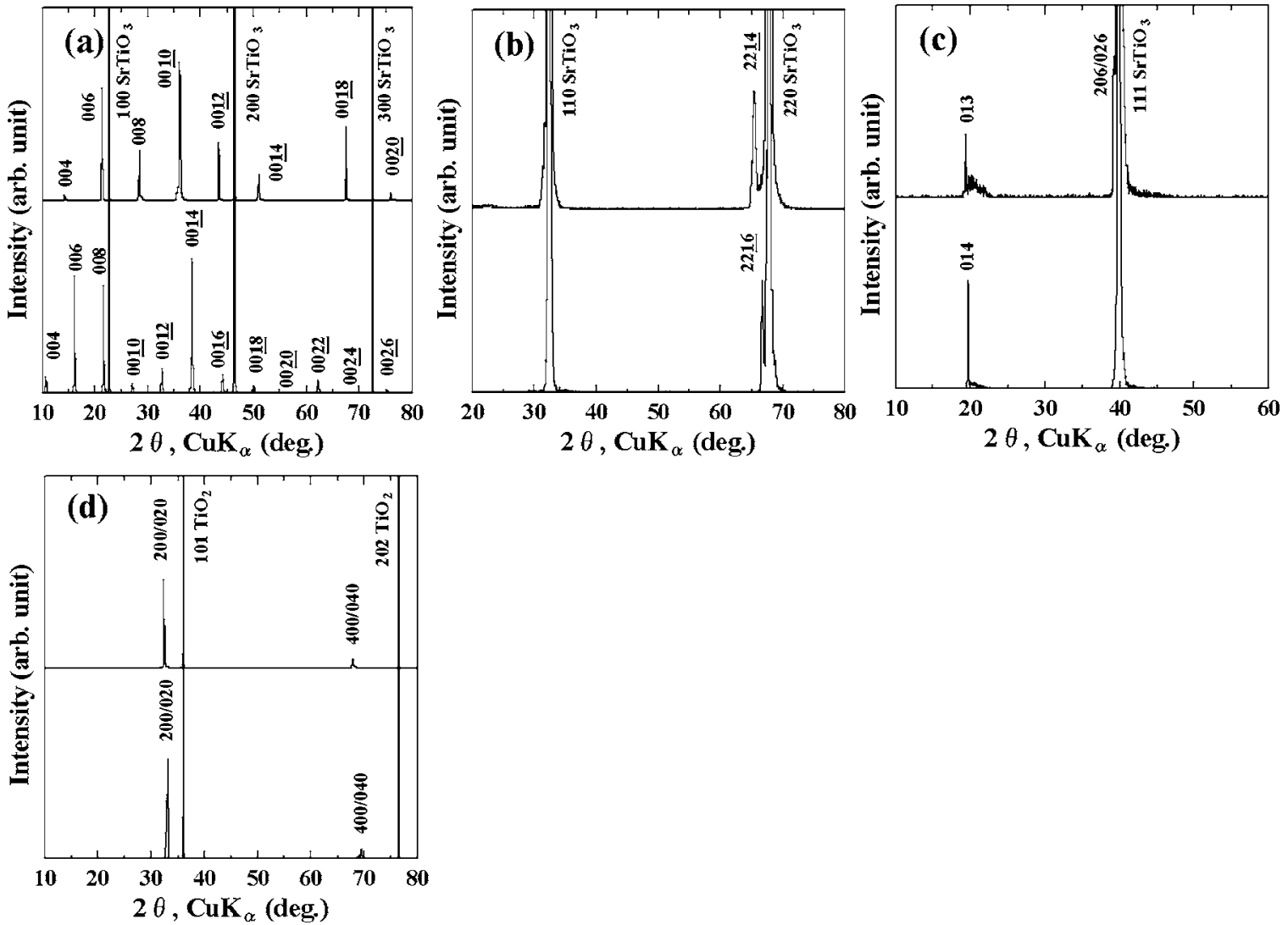

FIG. 2. X-ray $2 \theta-\theta$ scans of $\mathrm{SrBi}_{2} \mathrm{Ta}_{2} \mathrm{O}_{9}$ (upper) and $\mathrm{Bi}_{4} \mathrm{Ti}_{3} \mathrm{O}_{12}$ (bottom) films, epitaxially grown on (a) $(100) \mathrm{SrTiO}_{3},\left(\right.$ b) $(110) \mathrm{SrTiO}_{3}$, (c) (111) $\mathrm{SrTiO}_{3}$, and (d) $(101) \mathrm{TiO}_{2}$ single crystal substrates.

seen in Fig. 3, a set of four indexed diffractions grew from one crystal domain. Hence, the pole figures reveal that the films shown in Figs. 3(a)-3(d) had four-, two-, three-, and twofold twin growths, respectively. (If we consider the orthorhombic structure, the number of the twin growths doubles.) Figures 4 and 5 show the high-resolution transmission electron microscopy (TEM) images of the interface between the (001)SBT\| (100) $\mathrm{SrTiO}_{3}, \quad$ (116)SBT $\|(110) \mathrm{SrTiO}_{3}$, and (100)/(010)BIT\|(101) $\mathrm{TiO}_{2}$. Concerning the epitaxial BLSF film growth on the $\mathrm{SrTiO}_{3}$ substrates, the film orientation
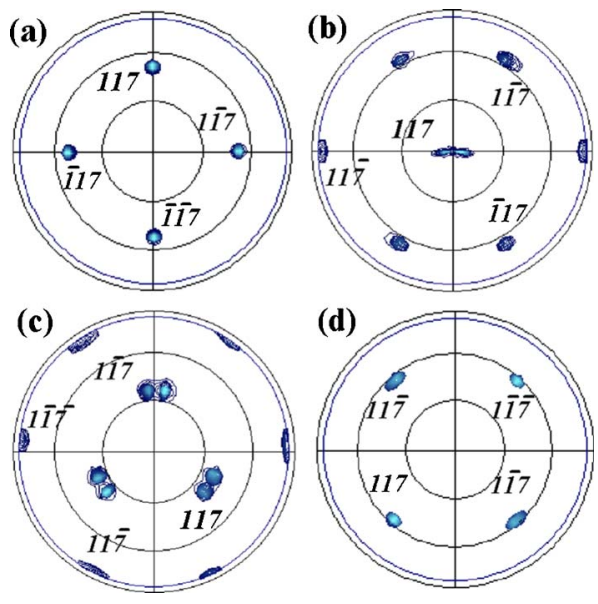

FIG. 3. (Color online) X-ray pole figures measured for (a) (001), (b) (118), (c) $(104) /(014)$, and (d) $(100) /(010) \mathrm{Bi}_{4} \mathrm{Ti}_{3} \mathrm{O}_{12}$ films shown in Fig. 2 . The fixed $2 \theta$ angle corresponds to $117 \mathrm{Bi}_{4} \mathrm{Ti}_{3} \mathrm{O}_{12}$. descriptions differ from those of simple perovskites that were epitaxially grown on $\mathrm{SrTiO}_{3}$ substrates, while keeping their structural coherency. However, the BLSF growth mechanism on the $\mathrm{SrTiO}_{3}$ substrates is similar to those of simple perovskites. The octahedrons in the pseudoperovskite layer also establish a continuous structural network with the octahedrons in the substrate.$^{55,74,75}$ Based on the misalignment of the pseudoperovskite unit from the $a$ - $/ b$-axis of approximately $45^{\circ}$, the $(001),(112 m+2)$, and $(10 m+1) /(01 m+1)$ BLSF orientations were almost comparable to the (100)/ (001), (110)/(101), and (111) orientations of simple tetragonal perovskites. The relationships between the crystal structure of substrates and the resultant film orientation were summarized into an epitaxial growth map..$^{70}$ The $(100) /(010)$ orientation that builds on long-range lattice matching is a unique BLSF epitaxial growth. For details, see Sec. IV. The (001), $(112 m+2),(10 m+1) /(01 m+1)$, and $(100) /(010)$ crystal growths were schematically drawn in Refs. 67 and 70.

To characterize the electric properties, we predeposited conductive materials with similar crystal structures to the substrate materials, such as $\mathrm{SrRuO}_{3}, \mathrm{RuO}_{2}$, and $\mathrm{IrO}_{2}$, onto the single crystal substrates. Figure 6 shows the orientation dependence of the polarization-electric field $(P-E)$ hysteresis loops measured for SBT or BIT films, epitaxially grown on $\mathrm{SrRuO}_{3} \| \mathrm{SrTiO}_{3}$ substrates. The (116)SBT and (118)BIT films exhibited a larger polarization than those of $c$-axis-oriented films. This is because the major $P_{s}$ vector along the $a$-axis is vertical to the applied electric field in the $c$-axis films and does not contribute to the polarization along 

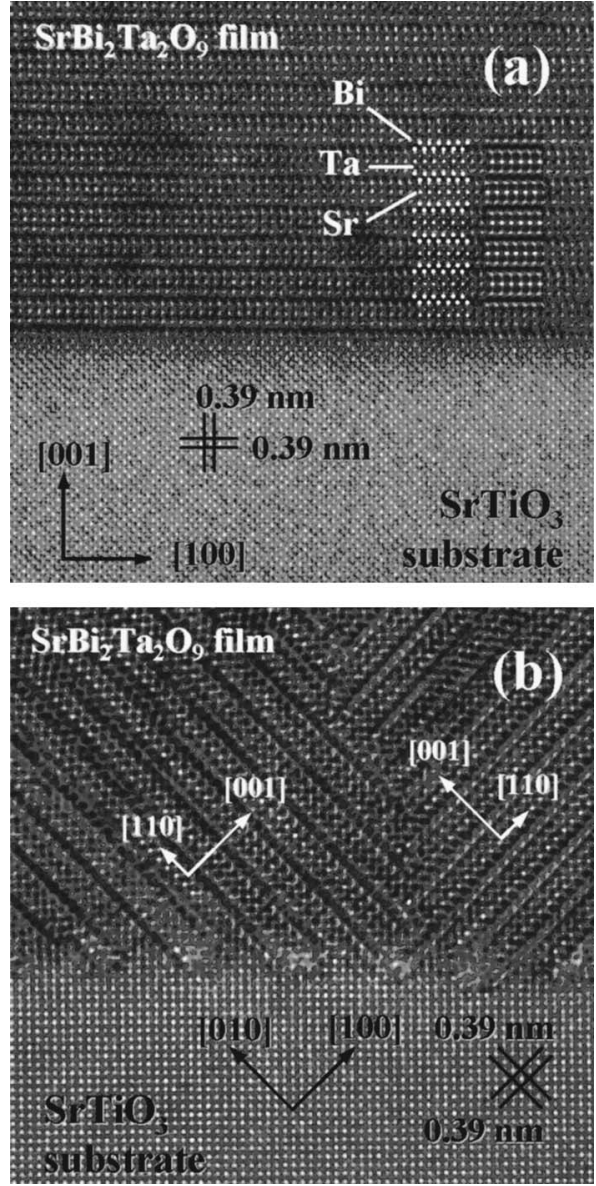

FIG. 4. High-resolution transmission electron microscopy images of the (a) (001) $\mathrm{SrBi}_{2} \mathrm{Ta}_{2} \mathrm{O}_{9} \|(100) \mathrm{SrTiO}_{3}$ and (b) (116) $\mathrm{SrBi}_{2} \mathrm{Ta}_{2} \mathrm{O}_{9} \|(110) \mathrm{SrTiO}_{3}$ interfaces.

the surface normal. The mirror plane perpendicular to the $c$-axis of SBT $(m=2$, even) is responsible for the not polarized $c$-axis-oriented film, as expected due to the structural symmetry. From the saturation polarization $\left(P_{\text {sat }}\right)$ given by the $y$ intercept of the tangent to the observed $P-E$ hysteresis loops, we can evaluate the $P_{s}$ (see Sec. V). The estimated $P_{s}$ from the present epitaxial films well agreed with those of high-quality bulk single crystals, ${ }^{67}$ so that the twodimensional stresses, e.g., misfit strain or thermal stress that is a specific subject to ultrathin epitaxial films on substrates, appeared to be relaxed by dislocations and stacking faults in the present epitaxial films with more than $200 \mathrm{~nm}$ thickness. The epitaxial growths on different single crystal substrates and conductive layers are summarized in Table II. $^{45-73}$

\section{FIBER-TEXTURED GROWTH AND FILM ORIENTATION CHARACTERIZATION}

With the increasing miniaturization or high integration of devices, multicrystal orientations in ferroelectric thin films have become a big issue. Ferroelectric grains with different crystal orientations are responsible for microscopically inhomogeneous switching charges and can cause bit-to-bit errors in the FeRAMs. To further increase device density, fibertextured growth of ferroelectric thin films on conventional metal electrode layers and reliable characterization of the
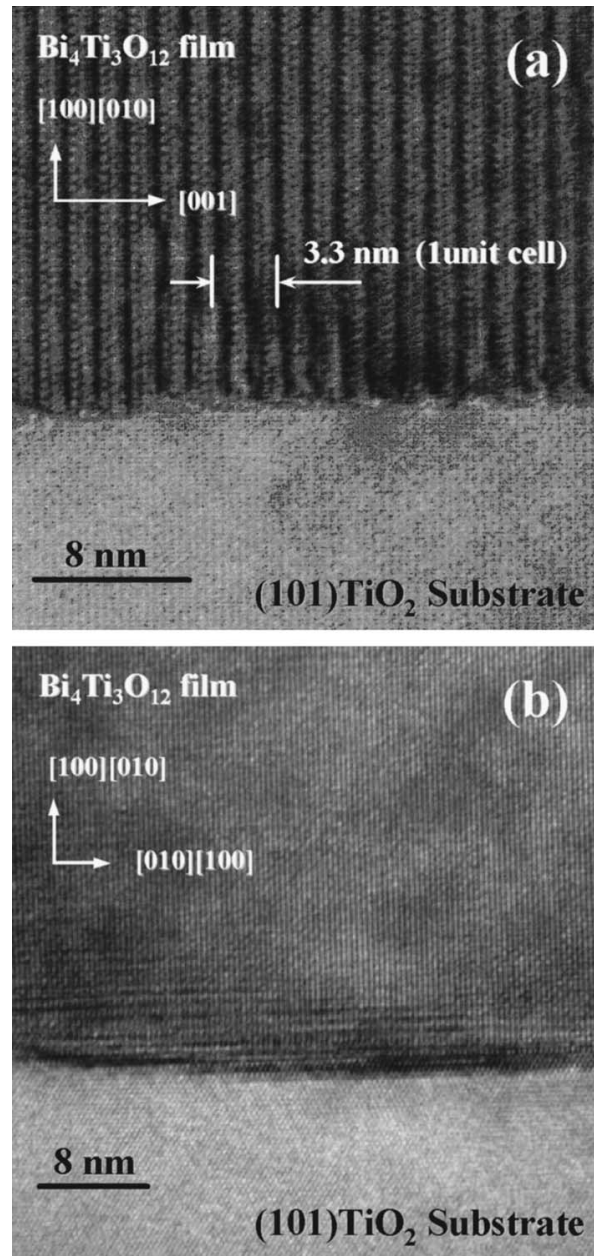

FIG. 5. Transmission electron microscopy images of the (100)/ (010) $\mathrm{Bi}_{4} \mathrm{Ti}_{3} \mathrm{O}_{12} \|(101) \mathrm{TiO}_{2}$ interface projected to rectangular in-plane directions: (a) $[100] /[010] \mathrm{Bi}_{4} \mathrm{Ti}_{3} \mathrm{O}_{12}$ and (b) $[001] \mathrm{Bi}_{4} \mathrm{Ti}_{3} \mathrm{O}_{12}$. Because of the twofold in-plane symmetry, the distinctive stacking of the pseudoperovskite and $\left(\mathrm{Bi}_{2} \mathrm{O}_{2}\right)^{2+}$ layers seen in (a) is not observed in (b), as seen from the rectangular azimuth.

film orientation will be important techniques. Fiber-textured growth implies a single crystal orientation without preferred in-plane orientation and is often built on the local epitaxial growth on the bottom crystal layer. Hence, the underlying crystal must have a similar fiber texture with low mosaicity.

Based on epitaxial film growth on (111) $\mathrm{SrTiO}_{3}$ substrate studies, ${ }^{63,67}(10 m+1) /(01 m+1)$ fiber-textured growth is expected for BLSF films deposited on (111)Pt and (111)Ir, which are conventional electrode materials. The film orientation is usually characterized using a conventional $\mathrm{x}$-ray $2 \theta-\theta$ scan, while the identification and quantification of the crystal orientations needs careful treatment because of the extremely different diffraction capabilities of the diffraction planes. For instance, the $112 m+1$ diffraction, which is the strongest peak in powder diffraction patterns, gives a large intensity to slightly incorporated $(112 m+1)$-oriented grains into the film, e.g., (117)BIT and (115)SBT. In contrast, a subtle $01 m+1$ diffraction $(10 m+1$ is forbidden) reveals that the major film orientation might be a $(10 m+1) /(01 m+1)$ orientation, even though the other diffraction peaks are higher than $01 m+1$. Conventional x-ray $2 \theta-\theta$ scans are limited to characterizing the film orientation only along the sur- 

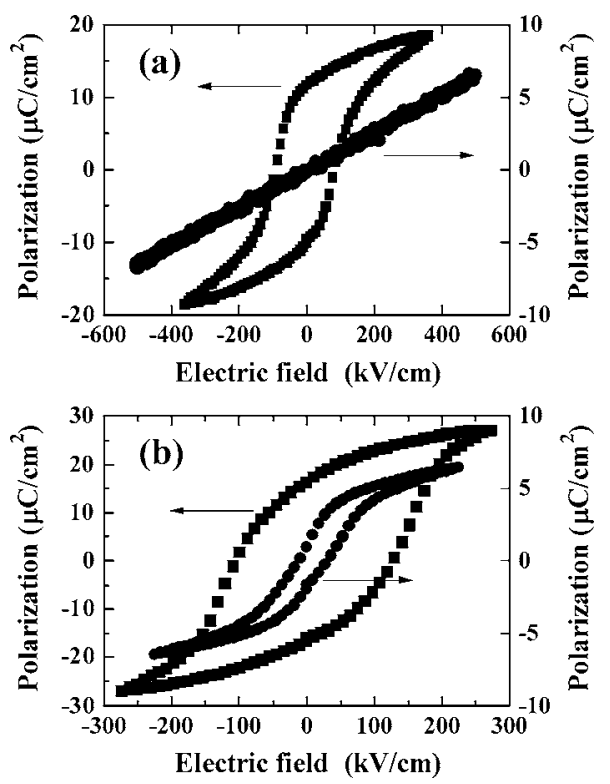

FIG. 6. Polarization-electric field hysteresis loops observed for epitaxial (a)

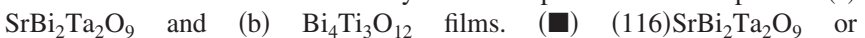
(118) $\mathrm{Bi}_{4} \mathrm{Ti}_{3} \mathrm{O}_{12}$ and $(001) \mathrm{SrBi}_{2} \mathrm{Ta}_{2} \mathrm{O}_{9}$ or $(001) \mathrm{Bi}_{4} \mathrm{Ti}_{3} \mathrm{O}_{12}$ films. The frequencies of the triangular electric fields were 1 and $20 \mathrm{~Hz}$ for $\mathrm{SrBi}_{2} \mathrm{Ta}_{2} \mathrm{O}_{9}$ and $\mathrm{Bi}_{4} \mathrm{Ti}_{3} \mathrm{O}_{12}$ films, respectively. The top circular electrode has a diameter of Pt of $100 \mu \mathrm{m}$, deposited using e-beam vacuum evaporation.

face normal, so it is difficult to precisely estimate the orientation if the structure factor of the corresponding diffraction plane is very small. Therefore, an additional method that can analyze the orientation not only along the surface normal but also in other directions is helpful to determine the film orientation and understand the impact of the crystal orientation on the observed polarization.

Saito et al. applied x-ray reciprocal space mapping performed using a $2 \theta-\theta$ scan at a wide range of $\psi$ (sample inclination angle normal to the scattering plane) to the SBT films deposited on the (111)Pt layer to distinguish the SBT phase with incorporated pyrochlore and fluorite phases and to quantify the volume fraction of each film orientation. ${ }^{76,77}$ Figure 7 shows the x-ray $2 \theta-\theta$ patterns of a BLT thin film prepared using MOCVD at $600{ }^{\circ} \mathrm{C}$ on a (111) $\mathrm{Pt} / \mathrm{Ti} / \mathrm{SiO}_{2} / \mathrm{Si}$ substrate. Figure 8 shows the $\mathrm{x}$-ray reciprocal space mappings measured for the film shown in Fig. 7. Figure 9 shows the $\psi$-angle dependence of the intensity integration in a $2 \theta$ pattern range from $29^{\circ}$ to $31^{\circ}$, as shown in Fig. 8. This range corresponds to around 117 BLT. At first glance, the film shown in Fig. 7 might appear to have no preferred orienta-

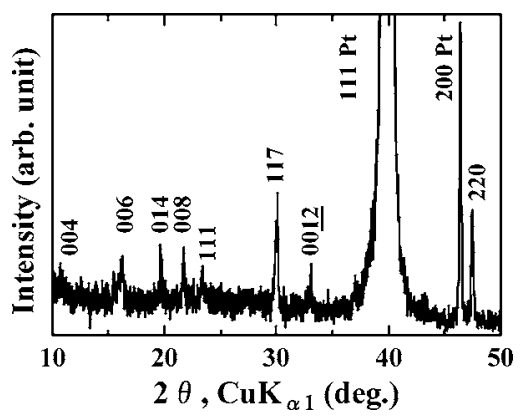

FIG. 7. X-ray $2 \theta-\theta$ pattern of BLT thin film prepared using metal organic chemical vapor deposition at $600{ }^{\circ} \mathrm{C}$ on a $\mathrm{Pt} / \mathrm{Ti} / \mathrm{SiO}_{2} /(100) \mathrm{Si}$ substrate.

tion because of the peaks originated from several diffraction planes. However, Figs. 8 and 9 clearly demonstrate that the film has a (104)/(014) preferred orientation. The $\psi$ angle and the 117 BIT multiplicity under a representative orientation assumption are listed in Table III. After dividing the peak intensities of the 117 BLT at different $\psi$ by their multiplicities, the resultant intensity ratio equals the volume fraction of the crystal orientations. (117 BIT at surface normal, $\psi=0^{\circ}$, is not available for quantification of the film orientation.) Focusing the $\psi$-angle dependence of the strong $11 \underline{2 m+1}$ diffraction, the film orientation and the volume fraction can be reliably evaluated. It is worth noting that a spot beam from a point-focused $\mathrm{x}$-ray tube can suppress the $\mathrm{x}$-ray divergence effect that occurs when the sample is inclined. A film without a preferred orientation will show a $11 \underline{2 m+1}$ diffraction at a constant intensity, irrespective of $\psi$. By optimizing the experimental conditions for the bottom electrode and BLSF films, we can obtain almost pure $(10 \underline{m+1}) /$ $(01 \underline{m+1})$-oriented films. ${ }^{78}$ However, the fiber-textured $(10 \underline{m+1}) /(01 \underline{m+1})$-oriented film might still exhibit a microscopic inhomogeneous switching charge, because almost no polarization is expected for the $(01 \underline{m+1})$ domain due to the lack of polarization from the $P_{s}$ along the $a$-axis. Although a fine $(10 \underline{m+1}) /(01 \underline{m+1})$ domain structure is probably created inside the crystal, we cannot be sure that the pure $(01 \underline{m+1})$-oriented grain penetrates the film toward the film surface, thus worsening the homogeneity in the microscopic switching charge. The $90^{\circ}$ switching of the $(01 \mathrm{~m}$ $+1)$-oriented grains and the approach to optimally $(10 m+1)$-oriented films are interesting studies for increasing device density. In Fig. 9, the density of a film deposited on $\mathrm{Ru} / \mathrm{SiO}_{2} / \mathrm{Si}$ is displayed for reference. The films grown on

TABLE II. Single crystal substrates and conductive bottom layer for epitaxial BLSF thin film growths.

\begin{tabular}{cccccc}
\hline \hline Film orientation & $(001)$ & $(11 \underline{2 m+1})$ & $(10 \underline{m+1}) /(01 \underline{m+1})$ & $(100) /(010)$ & $(110)$ \\
\hline Single crystal & $(100) \mathrm{SrTiO}_{3}$ & $(110) \mathrm{SrTiO}_{3}$ & $(111) \mathrm{SrTiO}_{3}$ & $(101) \mathrm{TiO}_{2}$ & $(100) \mathrm{LaSrAlO}_{4}$ \\
substrates & $(100) \mathrm{LaAl}_{2} \mathrm{O}_{3}$ & $(100) \mathrm{NdGaO}_{3}$ & & $(012) \mathrm{Al}_{2} \mathrm{O}_{3}$ & $(100) \mathrm{MgO}$ \\
& $(100) \mathrm{MgO}$ & & & $(110) \mathrm{MgO}$ & \\
& $(100) \mathrm{YSZ}$ & & & & \\
& $(001) \mathrm{Al}_{2} \mathrm{O}_{3}$ & & & $\mathrm{MgAl}_{2} \mathrm{O}_{4}$ & \\
Epitaxial & $(100) \mathrm{SrRuO}_{3}$ & $(110) \mathrm{SrRuO}_{3}$ & $(111) \mathrm{SrRuO}_{3}$ & $(101) \mathrm{RuO}_{2}$ & $(001) \mathrm{RuO}_{2}$ \\
conductive layer & $(100) \mathrm{Pt}$ & & $(111) \mathrm{Pt}_{0.5}$ & $(101) \mathrm{IrO}_{2}$ & \\
& $(001) \mathrm{La}_{0.5} \mathrm{Sr}_{0.5} \mathrm{CoO}_{3}$ & & $(111) \mathrm{La}_{0.5} \mathrm{Sr}_{0.5} \mathrm{CoO}_{3}$ & $(110) \mathrm{SrRuO}_{3}$ & \\
\hline \hline
\end{tabular}




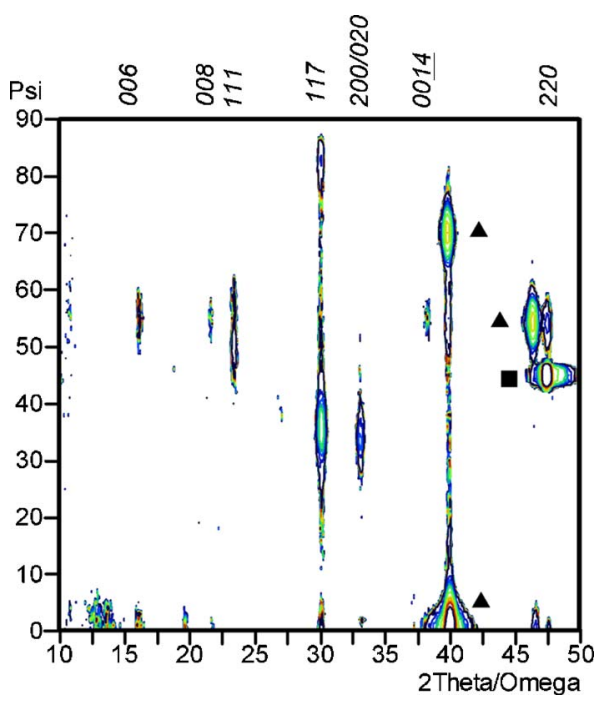

FIG. 8. (Color online) X-ray reciprocal space mapping, measured for the same film shown in Fig. 7. (ム) 111 and $220 \mathrm{Pt}$ come from the (111)Pt. (U) $220 \mathrm{Si}$ comes from the (100)Si.

the $\mathrm{Ru} / \mathrm{SiO}_{2} / \mathrm{Si}$ substrates have (110), (111), and (100)/(010) orientations, which are advantageous for large polarizations. As of yet, we have not been able to identify a preferred orientation. One reason for the multiorientations might be the oxidized Ru layer surface with nonuniform orientations.

\section{CHALLENGES FOR A-AXIS-ORIENTED FILMS}

Ferroelectricity along a specific crystal direction has been systematically investigated using various kinds of epitaxially grown BLSF films. However, direct characterization of the ferroelectricity along the [100] direction, including the polar axis, was limited to only bulk single crystals or thick films over $10 \mu \mathrm{m}$ that were peeled from the substrates. ${ }^{32-34}$ This is because there were no suitable bottom electrodes that can overcome these difficulties for the in-plane long-range lattice matching with a peculiar long $c$ axis. The lattice matching required for the $a-/ b$-axis-oriented BLSF thin film

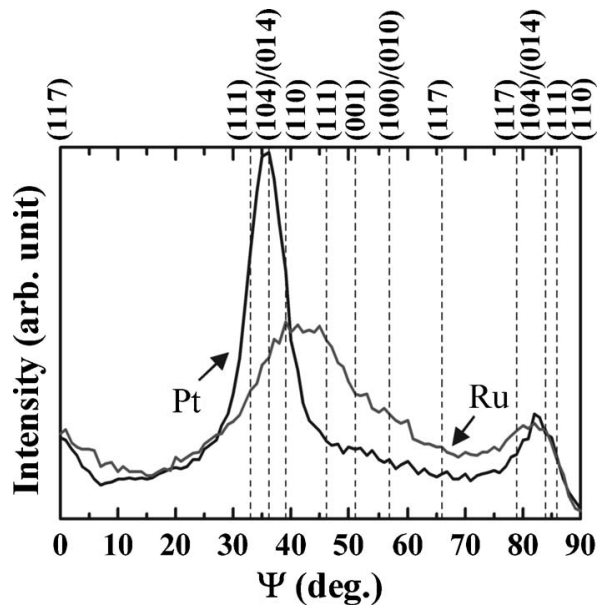

FIG. 9. $\psi$-angle dependence of the intensity integration at a $2 \theta$-pattern range of $29^{\circ}-31^{\circ}$, as shown in Fig. 8 .
TABLE III. Calculated $\psi$ angle and the multiplicity of 117 BIT for representative film orientations.

\begin{tabular}{ccc}
\hline \hline Film orientation & $\psi$ angle for 117 diffraction $(\mathrm{deg})$ & Multiplicity \\
\hline$(100) /(010)$ & 57 & 4 \\
$(110)$ & 39,90 & 2,2 \\
$(111)$ & $33,46,86$ & $1,1,2$ \\
$(117)$ & $0,66,79$ & $1,2,1$ \\
$(104) /(014)$ & 36,84 & 2,2 \\
$(001)$ & 51 & 4 \\
\hline \hline
\end{tabular}

growth is several times longer than that of the $a$-axis-oriented layer-structured superconductor $\mathrm{YBa}_{2} \mathrm{Cu}_{3} \mathrm{O}_{7-x}(c=1.17 \mathrm{~nm})$ thin films.

If we obtain $a$-(/b-)axis-oriented BLSF thin films that consist of metal-ferroelectric-metal structures, we can expect (1) to obtain larger remanent polarization, which is a great advantage for FeRAM applications, (2) to directly examine the possibility of $90^{\circ}$ domain switching believed to involve a large piezoelectric strain caused by an external electric field, and (3) to clarify the origin of the superior fatigue endurance of the BLSFs [i.e., the contribution of the $\left(\mathrm{Bi}_{2} \mathrm{O}_{2}\right)^{2+}$ layer parallel to the applied electric field]. It will also be interesting to see whether the $a$-axis-oriented BLSF thin films with vertically stacked octahedrons capable of penetrating the film thickness have good scalability. Furthermore, the sandwich structure consisting of two $\left(\mathrm{Bi}_{2} \mathrm{O}_{2}\right)^{2+}$ layer parts and a pseudoperovskite layer shows great promise for future applications, such as nanodot memories combined using a scanning probe technique. ${ }^{79,80}$

So far, two kinds of bottom electrodes are suitable for growing $a$ - $(/ b$-)axis-oriented films. One is (101)-oriented rutile-structured oxide, such as $\mathrm{RuO}_{2}$ and $\mathrm{IrO}_{2},{ }^{68,69}$ and the other is strained (110) $\mathrm{SrRuO}_{3}{ }^{50,51}$ The conductive (101)oriented rutile-structured oxides can be grown epitaxially on (101) $\mathrm{TiO}_{2}, \quad(012) \mathrm{Al}_{2} \mathrm{O}_{3}$, and (110) $\mathrm{Al}_{2} \mathrm{O}_{3}$ single crystal substrates. ${ }^{81}$ The $a$ - $/ b$-axis-oriented SBT $(m=2)$, BIT, and their modified derivatives $(m=3)$ and $\mathrm{SrBi}_{4} \mathrm{Ti}_{4} \mathrm{O}_{15}(m=4)$ were epitaxially grown on the rutile-structured layer using MOCVD. ${ }^{68,69,79}$ Matsuda et al. reported that BPT films prepared by chemical solution decomposition on the fibertextured (111)Ir layer showed a preferred $a$-axis orientation. They suggest that the preferred $a$-axis orientation of the BPT films arises from the surface (101) $\mathrm{IrO}_{2}$ layer, which is attributed to the surface oxidation of the (111)Ir layer during the process. ${ }^{44}$ Lee et al. grew epitaxially $a$-/ $b$-axis-oriented $\left(\mathrm{Bi}_{3.25} \mathrm{La}_{0.75}\right) \mathrm{Ti}_{3} \mathrm{O}_{12}$ films using pulsed laser deposition on stacked (110) $\mathrm{SrRuO}_{3} \|(100)$-oriented yttria-stabilized zirconiall(100)Si, and finally achieved pure $a$-axis-oriented films by optimizing the experiment conditions. ${ }^{50,51}$

Figure 10(a) shows a cross sectional TEM image of an epitaxial heterostructure of $(100) /(010) \mathrm{BIT} \|(101) \mathrm{TiO}_{2}$ projected to $[100] /[010]$ BIT. We clearly observed the stacking structure of the bismuth oxide and pseudoperovskite layers along the [001]BIT. For interfacial charge neutrality, the assumed atomic alignments at the interface are the titanium layer and the oxygen layer of the $\mathrm{TiO}_{2}$ and BIT, respectively. ${ }^{82}$ Figures 10 (b) and 10 (c) show selected-area 

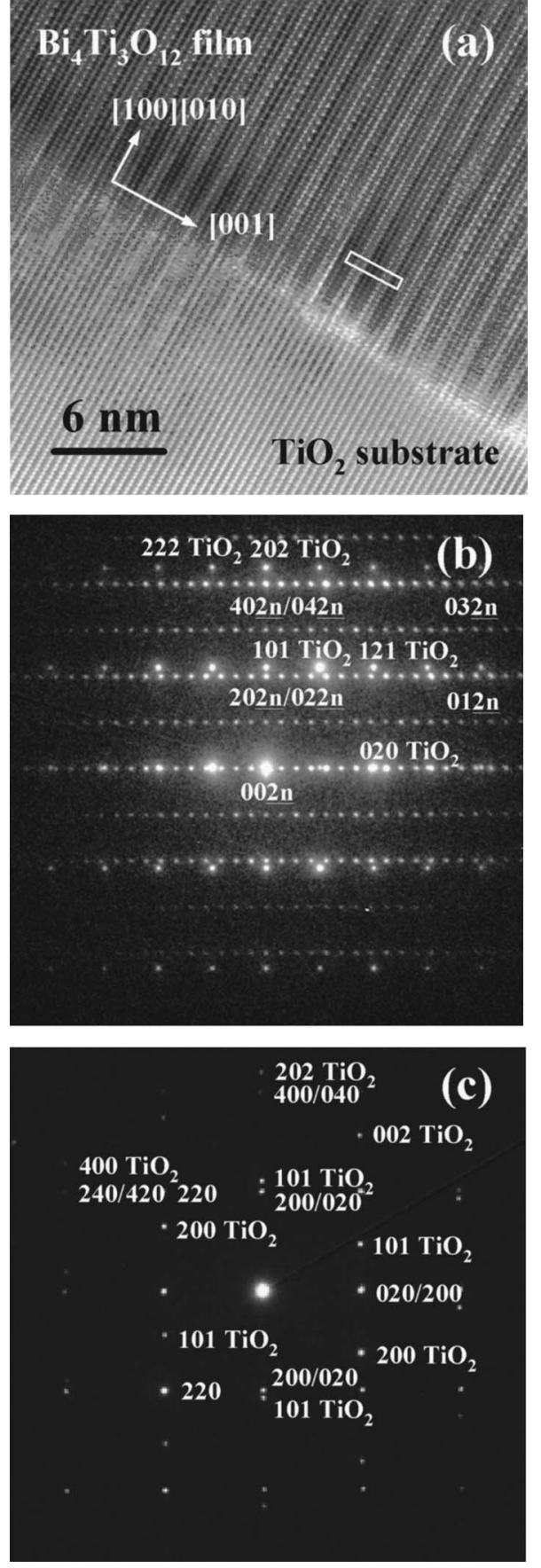

FIG. 10. (a) Cross-sectional high-resolution transmission electron microscopy image of an epitaxially grown $(100) /(010) \mathrm{Bi}_{4} \mathrm{Ti}_{3} \mathrm{O}_{12} \|(101) \mathrm{TiO}_{2}$ interface projected to $[100] /[010] \mathrm{Bi}_{4} \mathrm{Ti}_{3} \mathrm{O}_{12}$. The rectangle represents a one-unit lattice of $\mathrm{Bi}_{4} \mathrm{Ti}_{3} \mathrm{O}_{12}$ (about $0.54 \times 3.3 \mathrm{~nm}^{2}$ ). Selected-area electron diffraction patterns were projected to (b) $[100] /[010] \mathrm{Bi}_{4} \mathrm{Ti}_{3} \mathrm{O}_{12} \|[101] \mathrm{TiO}_{2}$ and (c) $[001] \mathrm{Bi}_{4} \mathrm{Ti}_{3} \mathrm{O}_{12} \|[010] \mathrm{TiO}_{2}$

electron diffraction patterns projected to $[100] /[010] \mathrm{BIT} \|[101] \mathrm{TiO}_{2}$ and $[001] \mathrm{BIT} \|[010] \mathrm{TiO}_{2}$, respectively. We observed two contrast patterns because of the twofold in-plane symmetry of the epitaxial growth. The transverse series of diffraction spots seen in Fig. 10(c) originated from the long $c$-axis lattice BIT parameter. From the inverse Fourier transformed images of Fig. 10(c) filtered for $008 \mathrm{BIT} / 010 \mathrm{TiO}_{2}$ spots and $0014 \mathrm{BIT} / 020 \mathrm{TiO}_{2}$ spots, we deduced reasonable lattice matching between the $a$ - $/ b$-axis-oriented BIT film and $(101) \mathrm{TiO}_{2}$ substrates to be

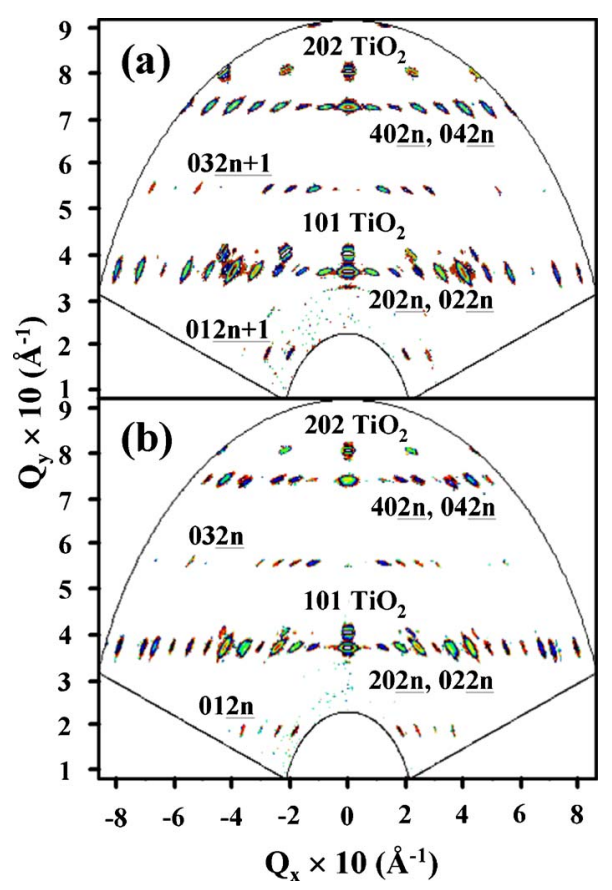

FIG. 11. (Color online) X-ray wide-area reciprocal space mappings of epitaxially grown (a) (100)/(010) $\mathrm{SrBi}_{2} \mathrm{Ta}_{2} \mathrm{O}_{9} \|(101) \mathrm{TiO}_{2}$ and (b) (100) $/(010) \mathrm{Bi}_{4} \mathrm{Ti}_{3} \mathrm{O}_{12} \|(101) \mathrm{TiO}_{2}$. The horizontal direction is parallel to $[001] \mathrm{SrBi}_{2} \mathrm{Ta}_{2} \mathrm{O}_{9},[001] \mathrm{Bi}_{4} \mathrm{Ti}_{3} \mathrm{O}_{12}$, and $[010] \mathrm{TiO}_{2}$.

seven $(101) \mathrm{TiO}_{2}$ units by one (100)/(010)BIT unit. ${ }^{82}$ Figures 11(a) and 11(b) show X-ray wide-range reciprocal space mappings for $a-/ b$-axis-oriented SBT and BIT films grown on $(101) \mathrm{TiO}_{2}$ substrates. The transverse distance to the next spot corresponds to $2 / c$ and clearly demonstrates that the $c$-axis of the SBT and BIT is parallel to the substrate surface. Due to the shorter $c$-axis lattice parameter of SBT, the interval of the horizontal series of diffraction peaks observed for SBT is longer than that for BIT. These figures exhibit homogeneous $a-/ b$-axis-oriented growths of SBT and BIT films deposited on (101) $\mathrm{TiO}_{2}$ substrates.

Figure 12(a) shows a conventional x-ray $2 \theta-\theta$ scan for a $\left(\mathrm{Bi}_{3.5} \mathrm{Nd}_{0.5}\right)\left(\mathrm{Ti}_{2.97} \mathrm{~V}_{0.03}\right) \mathrm{O}_{12}$ (BNTV) film grown on (012) $\mathrm{Al}_{2} \mathrm{O}_{3}$ substrate precovered with conductive (101) $\mathrm{RuO}_{2}$ for the following $P-E$ hysteresis measurement. The deposited BNTV film showed $a-/ b$-axis orientation, and the volume fraction of the $a / b$ domains was estimated to be almost $1: 1$ for this specimen. A clear $P-E$ hysteresis loop was observed for the BNTV film, as seen in Fig. 12(b). These films exhibited no behavior characteristics to the $90^{\circ}$ domain switching of the $b$ domain caused by the strong electric field. In common with the $a$ - $/ b$-axis-oriented SBT and BNTV films grown on the rutile-structured bottom electrodes, the observed polarization changed with the volume fraction of the $a / b$ domains in the films. ${ }^{68,69,83}$ Careful investigation is still required to determine the possibility of the $90^{\circ}$ domain switching of the $b$ domain. Chu et al. suggested a negligible polarization clamping of the $90^{\circ} a / b$ domains. ${ }^{84}$ An almost identical $P-E$ hysteresis loop was observed after $1.6 \times 10^{10}$ polarization switching, as shown in Fig. 12(b). Although the contribution of the oxide electrodes that improve ferroelec- 

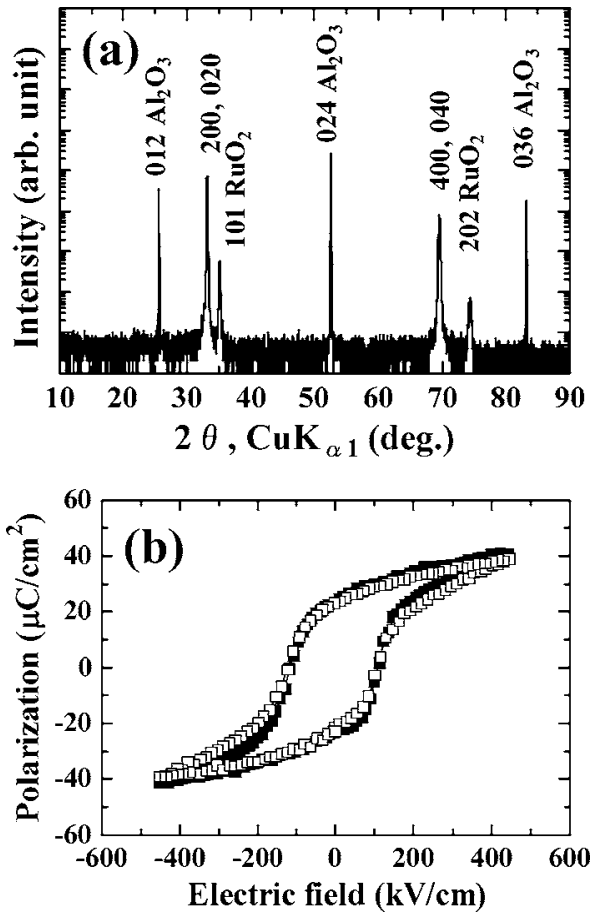

FIG. 12. (a) Conventional x-ray $2 \theta-\theta$ scan of epitaxially grown (100)/(010) $\left(\mathrm{Bi}_{3.5} \mathrm{Nd}_{0.5}\right)\left(\mathrm{Ti}_{2.97} \mathrm{~V}_{0.03}\right) \mathrm{O}_{12}\left\|(101) \mathrm{RuO}_{2}\right\|(012) \mathrm{Al}_{2} \mathrm{O}_{3}$ and (b) polarization-electric field hysteresis loops of a $\mathrm{Pt} /(100) /(010)\left(\mathrm{Bi}_{3.5} \mathrm{Nd}_{0.5}\right)$ $\times\left(\mathrm{Ti}_{2.97} \mathrm{~V}_{0.03}\right) \mathrm{O}_{12}\left\|(101) \mathrm{RuO}_{2}\right\|(012) \mathrm{Al}_{2} \mathrm{O}_{3}$ structure before (solid squares) and after (open squares) $1.6 \times 10^{10}$ switching cycles measured using a $20 \mathrm{~Hz}$ triangular wave. We performed a fatigue test using $100 \mathrm{kHz}$ rectangular pulses at the same amplitude used for the hysteresis measurement.

tric fatigue resistance ${ }^{85}$ was not verified, a high-fatigue resistance was confirmed for the $a$ - $/ b$-axis-oriented films ${ }^{68}$ and the pure $a$-axis-oriented film. ${ }^{50}$

\section{SPONTANEOUS POLARIZATION ESTIMATION}

The largest acceptable $P_{s}$ for BLSFs is $50 \mu \mathrm{C} / \mathrm{cm}^{2}$, reported for a BIT single crystal. ${ }^{13}$ However, no reasonably large polarization was observed in the BIT thin films, except for epitaxial films prepared at high temperatures. ${ }^{67}$ The BIT films prepared on Pt-covered substrates show fatigue failure. ${ }^{37,38}$ To overcome these drawbacks, lanthanoid and/or higher-valent cation substitutions for BIT that compensate for the defect complexes have been extensively investigated. ${ }^{8,15,16,18,19,36,38,41-44}$

At the same time, the lanthanoid substitutions for BIT were accompanied by a continuous decrease in $T_{C}{ }^{86,87}$ Therefore, the lanthanoid substitutions may sacrifice the original large $P_{s}$ of the parent BIT, because the $P_{s}$ reported for displacive ferroelectrics are generally inclined to $T_{C}{ }^{88}$ Understanding the relationship between the $P_{s}$ and $T_{C}$ of the BLSF system, including BIT-based materials, is invaluable for future material research. However, such systematic study is limited because bulk single crystals often form into a lateral plate with large $a$-/ $b$-plane facets due to their anisotropic crystal growth nature. Consequently, characterization of the electric properties along the $c$-axis is easy, but it is difficult along the $a-/ b$-axis. In addition, $\mathrm{Bi}_{2} \mathrm{O}_{3}$ used as flax for bulk single crystal fabrication affects the composition.

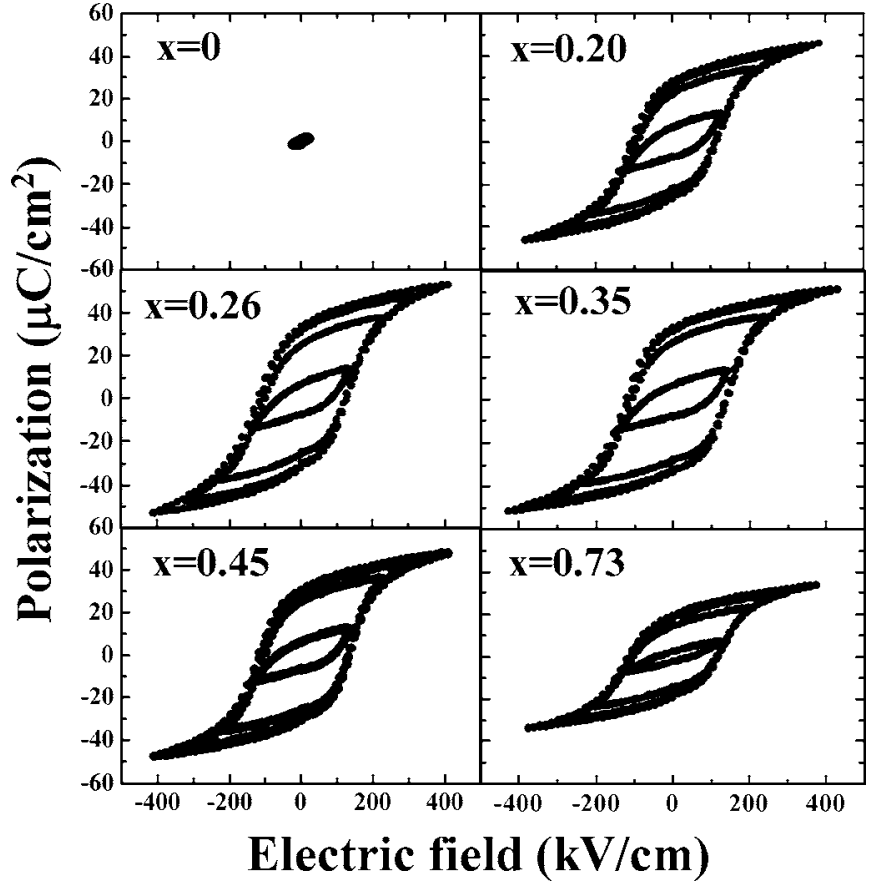

FIG. 13. Polarization-electric field hysteresis loops measured using $20 \mathrm{~Hz}$ triangular waves for $(110)\left(\mathrm{Bi}_{4-x} \mathrm{Nd}_{x}\right) \mathrm{Ti}_{3} \mathrm{O}_{12}$ films epitaxially grown on (001) $\mathrm{RuO}_{2} \|(001) \mathrm{TiO}_{2}$ substrates.

Alternatively, epitaxially grown films can be used to probe the $P_{s}$. The $P_{s}$ along the $c$-axis can easily be evaluated using $c$-axis-oriented epitaxial films, while there are various ways to explore the $P_{s}$ along the $a$-axis in combination with other characterizations. For instance, the $P_{s}$ estimation from $(10 \underline{m+1}) /(01 \underline{m+1})$ - or $(100) /(010)$-oriented films needs a volume fraction of both orientations. Furthermore, $90^{\circ}$ domain switching will be the next concern. This issue could be ignored for $(h h 1)$-oriented films, such as $(112 m+1)$-oriented ones, but the $P_{s}$ along the $c$-axis will still be necessary for the estimation. To simply estimate the $P_{s}$ along the $a$-axis, (110)-oriented films might be a reasonable choice under the assumption of full polarization switching by an external field. Excluding characterization of the domain volume fractions and the possibility of $90^{\circ}$ domain switching, the $P_{s}$ along the $a$-axis can be evaluated by multiplying the observed $P_{\text {sat }}$ by root 2 .

Figure 13 shows the $P-E$ hysteresis loops observed for the (110)-oriented $\left(\mathrm{Bi}_{4-x} \mathrm{Nd}_{x}\right)\left(\mathrm{Ti}_{2.97} \mathrm{~V}_{0.03}\right) \mathrm{O}_{12}$ films. This Ndsubstituted BIT is an emerging material with good potential as a lead-free alternative because of the large polarization and piezoelectric field-induced strain. ${ }^{89}$ Although the BIT film revealed an opened hysteresis loop for the strong electric field caused by the large leakage current, the Ndsubstituted films exhibited clear hysteresis loops.

On the basis of $P_{\text {sat }}$ and the $T_{C}$ characterization using Raman spectroscopy, ${ }^{90}$ the $P_{s}\left(P_{r}\right)-T_{C}$ relationships of a variety of ferroelectrics and the modified BIT are summarized in Fig. 14. The $P_{s}\left(P_{r}\right)$ of the BLSFs appears to be roughly linked to the $T_{C}$. The $P_{s}\left(P_{r}\right)$ of $\left(\mathrm{Bi}_{3.25} \mathrm{La}_{0.75}\right) \mathrm{Ti}_{3} \mathrm{O}_{12}\left(T_{C}\right.$ $\left.\approx 400{ }^{\circ} \mathrm{C}\right), 32-38 \mu \mathrm{C} / \mathrm{cm}^{2}$, is always higher than that of SBT $\left(T_{C} \approx 355-400{ }^{\circ} \mathrm{C}\right), 20-22 \mu \mathrm{C} / \mathrm{cm}^{2}$. Interestingly, an almost comparable magnitude of $P_{s}\left(P_{r}\right)$ as that of the parent 


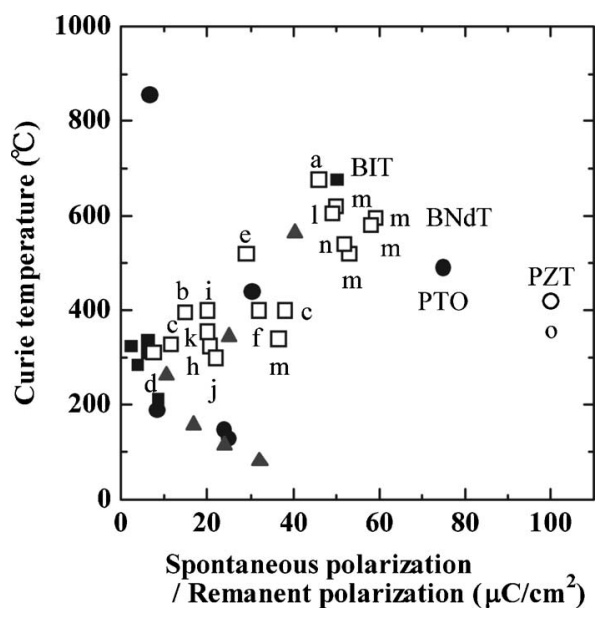

FIG. 14. $P_{s}\left(P_{r}\right)-T_{C}$ relationships in various displacive ferroelectrics. The closed symbols were cited from Ref. 88. $(\bullet, \bigcirc)$ Perovskite family, $(\boldsymbol{\Lambda})$ tungsten bronze family, and ( $\mathbf{\square}, \square$ ) Aurivillius family. (a) $\mathrm{Bi}_{4} \mathrm{Ti}_{3} \mathrm{O}_{12}$ single crystal $\left(P_{r}\right)$ (Ref. 14), (b) $\mathrm{BaBi}_{4} \mathrm{Ti}_{4} \mathrm{O}_{15}$ single crystal $\left(P_{r}\right)$ (Ref. 14), (c) $\mathrm{Ba}_{2} \mathrm{Bi}_{4} \mathrm{Ti}_{5} \mathrm{O}_{18}$ single crystal $\left(P_{r}\right)$ (Ref. 14), (d) $\mathrm{Pb}_{2} \mathrm{Bi}_{4} \mathrm{Ti}_{5} \mathrm{O}_{18}$ single crystal $\left(P_{r}\right)$ (Ref. 14), (e) $\mathrm{SrBi}_{4} \mathrm{Ti}_{4} \mathrm{O}_{15}$ single crystal $\left(P_{r}\right)$ (Ref. 91), (f) (118) $\times\left(\mathrm{Bi}_{3.25} \mathrm{La}_{0.75}\right) \mathrm{Ti}_{3} \mathrm{O}_{12}$ epitaxial film $\left(P_{s}\right) \quad($ Ref. 72$), \quad(\mathrm{g}) \quad(100)$ $\times\left(\mathrm{Bi}_{3.25} \mathrm{La}_{0.75}\right) \mathrm{Ti}_{3} \mathrm{O}_{12}$ epitaxial film $\left(P_{r}, T_{C}=400{ }^{\circ} \mathrm{C}\right.$ was assumed concerning the film composition) (Refs. 50 and 87), (h) $\left(\mathrm{Bi}_{3.15} \mathrm{La}_{0.85}\right) \mathrm{Ti}_{3} \mathrm{O}_{12}$ single crystal $\left(P_{r}, T_{C}=325{ }^{\circ} \mathrm{C}\right.$ was assumed concerning the single crystal composition) $\left(P_{r}\right)$ (Refs. 87 and 92), (i) (100)/(010) $\mathrm{Sr}_{0.8} \mathrm{Bi}_{2.2} \mathrm{Ta}_{2} \mathrm{O}_{9}$ epitaxial film $\left(P_{s}, T_{C}=400{ }^{\circ} \mathrm{C}\right.$ was assumed concerning the film composition) (Refs. 7 and 69), (j) (116) $\mathrm{SrBi}_{2} \mathrm{Ta}_{2} \mathrm{O}_{9}$ epitaxial film $\left(P_{s}, T_{C}=300{ }^{\circ} \mathrm{C}\right.$ was assumed concerning the film composition) (Refs. 7 and 60), (k) $\mathrm{SrBi}_{2} \mathrm{Ta}_{2} \mathrm{O}_{9}$ single crystal $\left(P_{s}\right)$ (Ref. 93), (1) (100)-fiber-textured $\left(\mathrm{Bi}_{3.7} \mathrm{Pr}_{0.3}\right) \mathrm{Ti}_{3} \mathrm{O}_{12}$ film $\left(P_{\text {sat }}\right)$ (Ref. 44), (m) (110) $\left(\mathrm{Bi}_{4-x} \mathrm{Ti}_{x}\right) \mathrm{Ti}_{3} \mathrm{O}_{12}$ epitaxial films $\left(P_{s}\right)$ (Ref. 43), (n) $\mathrm{Bi}_{4} \mathrm{Ti}_{3} \mathrm{O}_{12}-\mathrm{BaBi}_{4} \mathrm{Ti}_{4} \mathrm{O}_{15}$ single crystal $\left(P_{s}\right)$ (Ref. 24), (o) (001) $\mathrm{Pb}\left(\mathrm{Zr}_{0.35} \mathrm{Ti}_{0.65}\right) \mathrm{O}_{3}$ epitaxial film $\left(P_{\text {sat }}\right)$ (Ref. 94).

BIT is evaluated for BIT films modified using a small amount of lanthanoid $(x<0.5)$, or a superlattice structure, in spite of the reduced $T_{C}$. This means that the behavior of the $P_{s}\left(P_{r}\right)$ observed for the modified BIT is the result of multiple changes in the structural properties, e.g., pinning, the ionic displacement, and the dielectric stiffness affected by the substitution. Meanwhile, the results, the estimated $P_{s}$ of some BIT-based materials slightly exceeding $50 \mu \mathrm{C} / \mathrm{cm}^{2}$, might indicate that the intrinsic $P_{s}$ of a perfect BIT is larger than the conventional value. As can be seen for $\mathrm{SBT},{ }^{7,95}$ a substitution or solid solution that increases the $T_{C}$ of the BIT may enhance the $P_{s}$. Modifying the BIT with another element or compound will allow us to develop a lead-free material with higher $P_{s}$.

\section{PIEZOELECTRICITY}

Microelectromechanical systems (MEMSs) that use ferroelectric films as the driving part are another promising applications. As with FeRAMs, PZT-related ferroelectrics have been widely studied for MEMS applications because of their large piezoelectric coefficient and technical compatibility with $\mathrm{Si}$. Even though some $\mathrm{Pb}$-based perovskites contain costly substitution elements or are inadequate for single crystal preparation, their applications expand when they are in film form. However, the issue of environmental compatibility described previously is not addressed in this application. On the other hand, the BLSF's high $T_{C}$ and lead-free composition are favorable for piezoelectric applications.
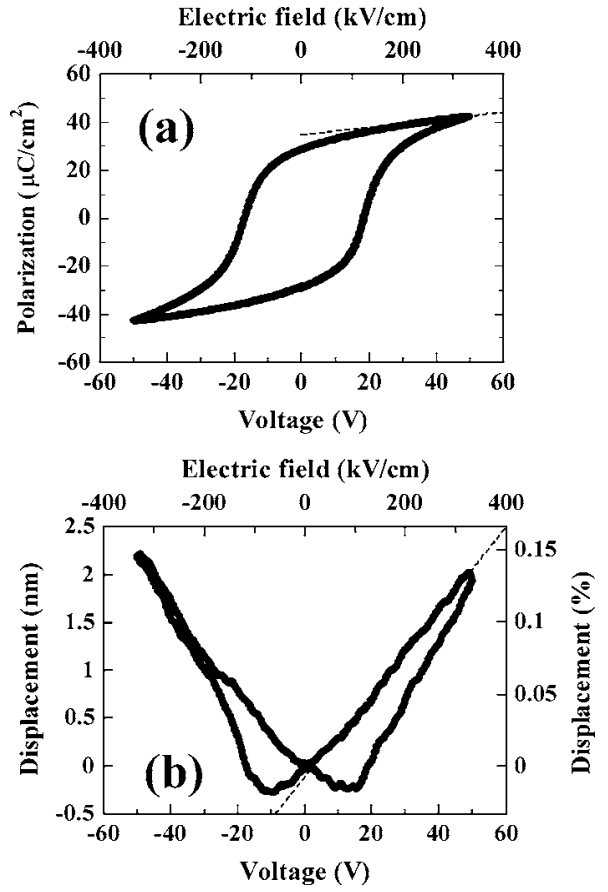

FIG. 15. (a) Polarization-electric field hysteresis and (b) field-induced strain $(S-E)$ loop observed for a 1.5 - $\mu$ m-thick epitaxial $(110)\left(\mathrm{Bi}_{3.54} \mathrm{Nd}_{0.46}\right)$ $\times\left(\mathrm{Ti}_{2.97} \mathrm{~V}_{0.03}\right) \mathrm{O}_{12}$ film grown on a $(001) \mathrm{RuO}_{2} \|(001) \mathrm{TiO}_{2}$ substrate. We used atomic force microscopy equipped with 100-nm-thick Rh-coated conductive cantilever $(k=15 \mathrm{~N} / \mathrm{m})$. The Pt $100 \mu \mathrm{m}$ diameter top electrodes were predeposited using e-beam vacuum evaporation. The measurement frequencies were 2 and $1 \mathrm{~Hz}$ for (a) and (b), respectively. For the $S$ - $E$ loop measurement, we recorded the $Z$ displacement of the piezoelectric scanner to keep the reflected laser position constant in the photodetector.

Based on a phenomenological equation $d=2 Q \varepsilon_{r} \varepsilon_{0} P_{s} E$ $\left(d, Q, \varepsilon_{r}, \varepsilon_{0}, P_{S}\right.$, and $E$ are the displacement, electrostrictive coefficient, relative dielectric constant, dielectric constant of vacuum, spontaneous polarization, and the electric field, respectively), larger displacement is expected in materials with larger $P_{s}$. Maiwa et al. reported that a $1-\mu \mathrm{m}$-thick $\left(\mathrm{Bi}_{3.25} \mathrm{Nd}_{0.75}\right) \mathrm{Ti}_{3} \mathrm{O}_{12}$ film prepared on a $\mathrm{Pt} / \mathrm{TiO}_{x} / \mathrm{SiO}_{2} / \mathrm{Si}$ substrate shows a larger relative dielectric constant and polarization than those of $\left(\mathrm{Bi}_{3.25} \mathrm{La}_{0.75}\right) \mathrm{Ti}_{3} \mathrm{O}_{12}$ and $\mathrm{Bi}_{4} \mathrm{Ti}_{3} \mathrm{O}_{12}$, so that the $\left(\mathrm{Bi}_{3.25} \mathrm{Nd}_{0.75}\right) \mathrm{Ti}_{3} \mathrm{O}_{12}$ film exhibits a larger displacement and piezoelectric constant $d_{33}=38 \mathrm{pm} / \mathrm{V} .{ }^{89}$ Figure 15 shows a $P-E$ hysteresis loop and a field-induced strain $(S-E)$ loop measured for a 1.5 - $\mu$ m-thick $(110)\left(\mathrm{Bi}_{3.54} \mathrm{Nd}_{0.46}\right)$ $\times\left(\mathrm{Ti}_{2.97} \mathrm{~V}_{0.03}\right) \mathrm{O}_{12}$ film, epitaxially grown on a $(001) \mathrm{RuO}_{2} \|(001) \mathrm{TiO}_{2}$ substrate using atomic force microscopy equipped with a conductive cantilever. The $P_{\text {sat }}$ and the relative dielectric constant were $35 \mu \mathrm{C} / \mathrm{cm}^{2}$ and 330 . The field-induced strain at $330 \mathrm{kV} / \mathrm{cm}$ was almost $1.3 \times 10^{-3}$, and the effective $d_{33}$ calculated from the gradient of the $S$-E loop was $44 \mathrm{pm} / \mathrm{V}$. The largest BLSF piezoelectric $d_{33}$ constant reported so far is $60 \mathrm{pm} / \mathrm{V}$ for a $1.5-\mu \mathrm{m}$-thick $\left(\mathrm{Bi}_{3.9} \mathrm{Pr}_{0.1}\right) \mathrm{Ti}_{3} \mathrm{O}_{12}$ film. ${ }^{96}$ These values, $d_{33}=40-60 \mathrm{pm} / \mathrm{V}$, are much larger than those of BIT ceramics, $d_{33}=20 \mathrm{pm} / \mathrm{V},{ }^{97}$ indicating that the lanthanoid substitution enhanced the piezoelectric performance of the parent BIT. The reported piezoelectric $d_{33}$ constant for the modified BIT films approaches those of PZT films, while the effect of the 
substitution, crystal orientation, geometry, and the characterization method on the observed piezoelectric properties has not yet been fully clarified for BLSF films.

\section{SUMMARY AND PROSPECTS}

In the last decade, a tremendous number of studies have been undertaken for BLSFs for FeRAM applications because of the beneficial fatigue- and lead-free environmental compatibility. Thin films were grown on a variety of substrates until the polar-axis-oriented growth on the conductive layer is achieved. We confirmed fiber-textured growth on the (111)Pt layer. However, the fiber-textured $(10 m+1) /$ $(01 \underline{m+1})$ orientation may exhibit microscopic inhomogeneous switching charges. Another progress is the improvement to the defect-related failures of the $\mathrm{Bi}_{4} \mathrm{Ti}_{3} \mathrm{O}_{12}$ crystal using lanthanoid and/or higher-valent cation substitutions. Substitution or a solid solution is necessary to improve the fatigue endurance and take advantage of the potentially large $P_{s}$ of the parent $\mathrm{Bi}_{4} \mathrm{Ti}_{3} \mathrm{O}_{12}$, just like $\mathrm{PbTiO}_{3}$-based materials. Reports on the $P_{s}$ and $d_{33}$ for modified $\mathrm{Bi}_{4} \mathrm{Ti}_{3} \mathrm{O}_{12}$ continue to increase, while further investigations are required to better understand the size effect, the squareness of the $P-E$ hysteresis loops, and piezoelectricity, related to the domain structure and dynamics.

Compared to the ferroelectric properties, the magnetic and piezoelectric properties of BLSFs are virtually unexplored. However, to expand the future applications of BLSFs, these properties will become very important. For example, BLSFs that contain $\mathrm{Mn}$ or $\mathrm{Fe}$ in the pseudoperovskite layer are expected to show multiferroic properties. Additionally, the piezoelectric properties of relaxor BLSFs are interesting. While it is well known that relaxor-type ferroelectrics show large electrostriction, similar studies have not been performed for BLSFs. By combining the recent progress in film orientation control and substitution techniques, we may be able to modify these properties.

\section{ACKNOWLEDGMENTS}

The authors would sincerely like to thank Dr. M. Fujimoto and Dr. T. Suzuki of Taiyo Yuden Co., Ltd., Dr. M. Osada and Professor M. Kakihana of Tokyo Institute of Technology, Professor M. Miyayama and Dr. Y. Noguchi of the University of Tokyo, Dr. H. Uchida and Professor I. Okada of Sophia University, Dr. K. Saito and M. Mizuhira of PANalytical, and Dr. N. Nukaga, K. Ishikawa, M. Mitsuya, T. Sakai, and T. Kojima of Tokyo Institute of Technology for collaboration. One of the authors (T.W.) is particularly grateful for receiving research fellowships from the Japan Society for the Promotion of Science for Young Scientists.

${ }^{1}$ B. Aurivillius, Ark. Kemi 1, 463 (1949).

${ }^{2}$ B. Aurivillius, Ark. Kemi 1, 499 (1949).

${ }^{3}$ R. E. Newnham, R. W. Wolfe, and J. F. Dorrian, Mater. Res. Bull. 6, 1029 (1971).

${ }^{4}$ A. D. Rae, J. G. Thompson, R. L. Withers, and A. C. Willis, Acta Crystallogr., Sect. B: Struct. Sci. B46, 474 (1990).

${ }^{5}$ S. K. Kim, M. Miyayama, and H. Yanagida, Mater. Res. Bull. 31, 121 (1996).

${ }^{6}$ Y. Noguchi, M. Miyayama, and T. Kudo, Phys. Rev. B 63, 214102 (2001).

${ }^{7}$ Y. Shimakawa, Y. Kubo, Y. Nakagawa, T. Kamiyama, H. Asano, and F.
Izumi, Appl. Phys. Lett. 74, 1904 (1999).

${ }^{8}$ Y. Shimakawa, Y. Kubo, Y. Tauchi, H. Asano, T. Kamiyama, F. Izumi, and Z. Hiroi, Appl. Phys. Lett. 79, 2791 (2001).

${ }^{9}$ G. A. Smolenskii, V. A. Isupov, and A. I. Agranovskaya, Sov. Phys. Solid State 3, 651 (1961)

${ }^{10}$ E. C. Subbarao, J. Am. Ceram. Soc. 45, 166 (1961).

${ }^{11}$ E. C. Subbarao, Phys. Rev. 122, 804 (1961).

${ }^{12}$ E. C. Subbarao, J. Phys. Chem. Solids 23, 665 (1962).

${ }^{13}$ S. E. Cummins and L. E. Cross, J. Appl. Phys. 39, 2268 (1968).

${ }^{14}$ H. Irie, M. Miyayama, and T. Kudo, J. Appl. Phys. 90, 4089 (2001).

${ }^{15}$ Y. Noguchi, I. Miwa, Y. Goshima, and M. Miyayama, Jpn. J. Appl. Phys., Part 2 39, L1259 (2000).

${ }^{16}$ Y. Noguchi and M. Miyayama, Appl. Phys. Lett. 78, 1903 (2001).

${ }^{17}$ R. W. Wolfe and R. E. Newnham, J. Electrochem. Soc. 116, 832 (1969).

${ }^{18}$ T. Watanabe, H. Funakubo, M. Osada, Y. Noguchi, and M. Miyayama, Appl. Phys. Lett. 80, 100 (2002).

${ }^{19}$ T. Watanabe, T. Kojima, T. Sakai, H. Funakubo, M. Osada, Y. Noguchi, and M. Miyayama, J. Appl. Phys. 92, 1518 (2002).

${ }^{20}$ T. Kikuchi, J. Less-Common Met. 48, 319 (1976).

${ }^{21}$ T. Kikuchi, A. Watanabe, and K. Uchida, Mater. Res. Bull. 12, 299 (1977).

${ }^{22}$ S. Luo, Y. Noguchi, M. Miyayama, and T. Kudo, Mater. Res. Bull. 36, 531 (2001).

${ }^{23}$ Y. Noguchi, M. Miyayama, and T. Kudo, Appl. Phys. Lett. 77, 3639 (2000).

${ }^{24}$ T. Kobayashi, Y. Noguchi, and M. Miyayama, Appl. Phys. Lett. 86, 012907 (2005).

${ }^{25}$ W. J. Yu, Y. I. Kim, D. H. Ha, J. H. Lee, Y. K. Park, S. Seong, and N. H. Hur, Solid State Commun. 111, 705 (1999).

${ }^{26}$ M. I. Morozov and V. V. Gusarov, Inorg. Mater. 38, 723 (2002).

${ }^{27}$ C. H. Hervoches, A. Snedden, R. Riggs, S. H. Kilcoyne, P. Manuel, and P. Lightfoot, J. Solid State Chem. 164, 280 (2002).

${ }^{28}$ A. Snedden, C. H. Hervoches, and P. Lightfoot, Phys. Rev. B 67, 092102 (2003).

${ }^{29}$ E. E. McCabe and C. Geaves, J. Mater. Chem. 15, 177 (2005).

${ }^{30}$ S. Ikegami and I. Ueda, Jpn. J. Appl. Phys. 13, 1572 (1974).

${ }^{31}$ W. J. Takei, N. P. Formigoni, and M. H. Francombe, J. Vac. Sci. Technol. 7, 442 (1970).

${ }^{32}$ W. J. Takei, N. P. Formigoni, and M. H. Francombe, Appl. Phys. Lett. 15, 256 (1969)

${ }^{33}$ S. Y. Wu, W. J. Takei, and M. H. Francombe, Appl. Phys. Lett. 22, 26 (1972).

${ }^{34}$ S. Y. Wu, W. J. Takei, M. H. Francombe, and S. E. Cummins, Ferroelectrics 3, 217 (1972).

${ }^{35}$ C. A. Paz de Araujo, J. D. Cuchiaro, L. D. McMillan, M. C. Scott, and J. F. Scott, Nature (London) 374, 627 (1995).

${ }^{36}$ B. H. Park, B. S. Kang, S. D. Bu, T. W. Noh, L. Lee, and W. Joe, Nature (London) 401, 682 (1999).

${ }^{37}$ P. C. Joshi, S. B. Krupanidhi, and A. Mansingh, J. Appl. Phys. 72, 5517 (1992).

${ }^{38}$ D. Wu, A. Li, T. Zhu, Z. Li, Z. Liu, and N. Ming, J. Mater. Res. 16, 1325 (2001).

${ }^{39}$ B. H. Park, S. J. Hyun, S. D. Bu, T. W. Noh, J. Lee, H.-D. Kim, T. H. Kim, and W. Jo, Appl. Phys. Lett. 74, 1907 (1999).

${ }^{40}$ Y. Ding, J. S. Liu, H. X. Qin, J. S. Zhu, and Y. N. Wang, Appl. Phys. Lett. 78, 4175 (2001).

${ }^{41}$ H. Uchida, H. Yoshikawa, I. Okada, H. Matsuda, T. Iijima, T. Watanabe, T. Kojima, and H. Funakubo, Appl. Phys. Lett. 81, 2229 (2002).

${ }^{42}$ H. Uchida, H. Yoshikawa, I. Okada, H. Matsuda, T. Iijima, T. Watanabe, T. Kojima, and H. Funakubo, Jpn. J. Appl. Phys., Part 1 41, 6820 (2002).

${ }^{43}$ T. Watanabe, H. Funakubo, M. Osada, H. Uchida, and I. Okada, J. Appl. Phys. 98, 024110 (2005).

${ }^{44}$ H. Matsuda, S. Ito, and T. Iijima, Appl. Phys. Lett. 83, 5023 (2003).

${ }^{45}$ W. Jo, K. H. Kim, and T. W. Noh, Appl. Phys. Lett. 66, 3120 (1995).

${ }^{46}$ B. H. Park, T. W. Noh, J. Lee, C. Y. Kim, and W. Jo, Appl. Phys. Lett. 70, 1101 (1997).

${ }^{47}$ S. E. Moon, T. K. Song, S. B. Back, S.-I. Kwun, J.-G. Yoon, and J. S. Lee, Appl. Phys. Lett. 75, 2827 (1999).

${ }^{48}$ H. N. Lee, A. Visinoiu, S. Senz, C. Harnagea, A. Pignolet, D. Hesse, and U. Gösele, J. Appl. Phys. 88, 6658 (2000).

${ }^{49}$ H. N. Lee and D. Hesse, Appl. Phys. Lett. 80, 1040 (2002).

${ }^{50}$ H. N. Lee, D. Hesse, N. Zakharov, and U. Gösele, Science 296, 2006 (2002).

${ }^{51}$ H. N. Lee, D. Hesse, N. Zakharov, S. K. Lee, and U. Gösele, J. Appl. 
Phys. 93, 5592 (2003)

${ }^{52}$ A. Garg, Z. H. Barber, M. Dawber, J. F. Scott, A. Snedden, and P. Lightfoot, Appl. Phys. Lett. 83, 2414 (2003).

${ }^{53}$ J. Lettieri et al., Appl. Phys. Lett. 73, 2923 (1998).

${ }^{54}$ C. D. Theis, J. Yeh, D. G. Schlom, M. E. Hawley, G. W. Brown, J. C. Jiang, and X. Q. Pan, Appl. Phys. Lett. 72, 2817 (1998).

${ }^{55}$ M. A. Zurbuchen, J. Lettieri, Y. Jia, D. G. Schlom, S. K. Streiffer, and M. E. Hawley, J. Mater. Res. 16, 489 (2001).

${ }^{56}$ D. G. Schlom, J. H. Haeni, J. Lettieri, C. D. Theis, W. Tian, J. C. Jiang, and X. Q. Pan, Mater. Sci. Eng., B B87, 282 (2001).

${ }^{57}$ M. A. Zurbuchen, G. Asayama, D. G. Schlom, and S. K. Streiffer, Phys. Rev. Lett. 88, 107601 (2002).

${ }^{58}$ X. Q. Pan, J. C. Jiang, C. D. Theis, and D. G. Schlom, Appl. Phys. Lett. 83, 2315 (2003).

${ }^{59}$ S. Chattopadhyay et al., Appl. Phys. Lett. 78, 3514 (2001).

${ }^{60}$ K. Ishikawa and H. Funakubo, Appl. Phys. Lett. 75, 1970 (1999).

${ }^{61}$ K. Ishikawa, H. Funakubo, K. Saito, T. Suzuki, Y. Nishi, and M. Fujimoto, J. Appl. Phys. 87, 8018 (2000).

${ }^{62}$ K. Ishikawa, N. Nukaga, and H. Funakubo, Jpn. J. Appl. Phys., Part 238 , L258 (1999).

${ }^{63}$ K. Ishikawa, A. Saiki, and H. Funakubo, Jpn. J. Appl. Phys., Part 1 39, $2102(2000)$.

${ }^{64}$ K. Ishikawa, T. Watanabe, and H. Funakubo, Thin Solid Films 392, 128 (2001).

${ }^{65}$ T. Sakai, T. Watanabe, Y. Cho, K. Matsuura, and H. Funakubo, Jpn. J. Appl. Phys., Part 1 40, 6481 (2001)

${ }^{66}$ T. Watanabe, A. Saiki, K. Saito, and H. Funakubo, J. Appl. Phys. 89, 3934 (2001).

${ }^{67}$ T. Watanabe, H. Funakubo, and K. Saito, J. Mater. Res. 16, 303 (2001).

${ }^{68}$ T. Watanabe, H. Funakubo, K. Saito, T. Suzuki, M. Fujimoto, M. Osada, Y. Noguchi, and M. Miyayama, Appl. Phys. Lett. 81, 1660 (2002).

${ }^{69}$ T. Watanabe et al., Jpn. J. Appl. Phys., Part 2 41, L1478 (2002).

${ }^{70}$ T. Watanabe and H. Funakubo, Jpn. J. Appl. Phys., Part 1 44, 1337 (2005).

${ }^{71}$ T. Kojima, T. Sakai, T. Watanabe, H. Funakubo, K. Saito, and M. Osada, Appl. Phys. Lett. 80, 2746 (2002).

${ }^{72}$ T. Sakai, T. Watanabe, H. Funakubo, K. Saito, and M. Osada, Jpn. J. Appl. Phys., Part 1 42, 166 (2003).

${ }^{73}$ T. Kojima, T. Watanabe, H. Funakubo, K. Saito, M. Osada, and M. Kakihana, J. Appl. Phys. 93, 1707 (2003).

${ }^{74}$ T. Suzuki, Y. Nishi, M. Fujimoto, K. Ishikawa, and H. Funakubo, Jpn. J. Appl. Phys., Part 2 38, L1261 (1999).
${ }^{75}$ T. Suzuki, Y. Nishi, M. Fujimoto, K. Ishikawa, and H. Funakubo, Jpn. J. Appl. Phys., Part 2 38, L1265 (1999).

${ }^{76}$ K. Saito, M. Mitsuya, N. Nukaga, I. Yamaji, T. Akai, and H. Funakubo, Jpn. J. Appl. Phys., Part 1 39, 5489 (2000).

${ }^{77}$ K. Saito, I. Yamaji, T. Akai, M. Mitsuya, and H. Funakubo, Jpn. J. Appl. Phys., Part 1 42, 539 (2003).

${ }^{78}$ N. Nukaga, M. Mitsuya, T. Suzuki, Y. Nishi, M. Fujimoto, and H. Funakubo, Jpn. J. Appl. Phys., Part 1 40, 5595 (2001).

${ }^{79}$ T. Watanabe and H. Funakubo, J. Solid State Chem. 178, 64 (2005).

${ }^{80}$ H. Odagawa and Y. Cho, Appl. Phys. Lett. 80, 2159 (2002).

${ }^{81}$ T. Watanabe, M. Osada, K. Saito, and H. Funakubo, Mater. Res. Soc. Symp. Proc. 688, 155 (2002).

${ }^{82}$ T. Watanabe, M. Osada, K. Saito, and H. Funakubo, Mater. Res. Soc. Symp. Proc. 748, U.2.4 (2003).

${ }^{83}$ T. Watanabe, H. Morioka, S. Okamoto, M. Takahashi, Y. Noguchi, M. Miyayama, and H. Funakubo, Mater. Res. Soc. Symp. Proc. 784, C.4.2 (2004).

${ }^{84}$ M.-W. Chu, S. K. Lee, D. Hesse, and U. Gösele, Appl. Phys. Lett. 85, 2029 (2004).

${ }^{85}$ S.-H. Kim, J. G. Hong, S. K. Streiffer, and A. I. Kingon, J. Mater. Res. 14, 1018 (1999)

${ }^{86}$ T. Takenaka and K. Sakata, Ferroelectrics 38, 769 (1981).

${ }^{87}$ M. Osada, M. Tada, M. Kakihana, T. Watanabe, and H. Funakubo, Jpn. J. Appl. Phys., Part 1 40, 5572 (2001).

${ }^{88}$ K. Singh, D. K. Bopardikar, and D. V. Atkare, Ferroelectrics 82, 55 (1988).

${ }^{89}$ H. Maiwa, N. Iizawa, D. Togawa, T. Hayashi, W. Sakamoto, M. Yamada, and S. Hirano, Appl. Phys. Lett. 82, 1760 (2003).

${ }^{90}$ T. Watanabe, M. Mizuhira, M. Osada, and H. Funakubo, J. Appl. Phys. 90, 6533 (2001)

${ }^{91}$ H. Irie and M. Miyayama, Appl. Phys. Lett. 79, 251 (2001).

${ }^{92}$ M. Soga, Y. Noguchi, M. Miyayama, H. Okino, and T. Yamamoto, Appl. Phys. Lett. 84, 100 (2004).

${ }^{93}$ H. Amorín, V. V. Shvartsman, A. L. Kholkin, and M. E. V. Costa, Appl. Phys. Lett. 85, 5667 (2004).

${ }^{94}$ H. Morioka, G. Asano, T. Oikawa, H. Funakubo, and K. Saito, Appl. Phys. Lett. 82, 4761 (2003).

${ }^{95}$ M. Mitsuya, M. Osada, K. Saito, and H. Funakubo, J. Cryst. Growth 237-239, 473 (2002).

${ }^{96}$ H. Matsuda, S. Ito, and T. Iijima, Appl. Phys. Lett. 85, 1220 (2004).

${ }^{97}$ E. C. Subbarao, IRE Trans. Electron Devices ED8, 422 (1961). 